\title{
Martirio y arrebato en la apocalíptica judía. Una propuesta de estética teológico-bíblica
}

\author{
César Carbullanca N. \\ FACULTAD DE CIENCIAS RELIGIOSAS Y FILOSÓFICAS \\ UNIVERSIDAD CATÓLICA DEL MAULE \\ carbullanca@yahoo.com
}

\section{INTRODUCCIÓN}

Diversos investigadores contemporáneos como R. Bultmann, E. Käsemann, W. Pannenberg; J. Moltmann y J. Sobrino se han sensibilizado al influjo de la apocalíptica y de la importancia del futuro en la teología ${ }^{1}$. En todos estos autores se produce un "regreso a la apocalíptica" como matriz teórica para pensar el mensaje cristiano en el mundo actual. Ciertamente de diferente manera. J. Moltmann, en su teología, dialoga con el principio esperanza que postula E. Bloch; a su vez W. Pannenberg pretende una nueva fundamentación de la cristología para lo cual se inspira en la filosofía de la historia de $\mathrm{Hegel}^{2}$. Y J. Sobrino intenta un diálogo con la realidad latinoamericana desde las víctimas. En su libro La fe en Jesucristo ${ }^{3}$, se sensibiliza a esta perspectiva apocalíptica. Haciendo referencia a la teología contemporánea europea tratada en la primera parte de su libro, sosteniendo que dicha teología ha recuperado mucho del sentido original de la fe en la resurrección, el cuerpo, la apertura al futuro, la estructura antropológica de la esperanza, etc.; no obstante, olvida un aspecto esencial: "hacer justicia a las víctimas", y por esto

1 E. Käsemann (ed.), Exegetische Versuche und Besinnungen (Vandenhoeck \& Ruprecht, Göttingen, ' 1970); J. Moltmann, Teología de la Esperanza (Sígueme, Salamanca, 1969); J. Sobrino, Cristología desde América Latina. Esbozo a partir del seguimiento del Jesús histórico (CRT ediciones, México, ${ }^{2} 1977$ ).

2 W. Pannenberg, Grundzuge der Christologie (Güterloher Verlaghaus, Güterloher, 1964) 7.

3 J. Sobrino, La fe en Jesucristo. Ensayo desde las víctimas (Trotta, Madrid, 1999) 33. 
"hay que volver a la apocalíptica... su esperanza versa en directo sobre la justicia, no simplemente sobre la supervivencia; sus sujetos primarios

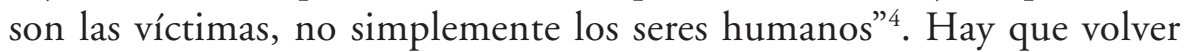
a la apocalíptica en un contexto donde la muerte ya no es, ni mítica ni metafísica, sino comprendida a partir de la racionalidad científica que olvida el sentido autobiográfico del sujeto y el sentido que quiso dar a ese acto final.

Nosotros queremos profundizar en esta constante presente en la teología contemporánea; sobre todo en la perspectiva teológica de Jon Sobrino; profundización que, siendo consecuente con la reflexión apocalíptica, pretende ser un puente, un pensar de nuevo en y desde las metáforas de la muerte violenta y la entrega de la vida por Dios.

Desde una perspectiva histórico-bíblica, la cuestión teológica del sentido de la muerte violenta emerge a la conciencia bíblica durante la época helenista, sobre todo en relación al tema de la justicia de Dios y de dar la vida o de la muerte por la Ley o por el pueblo. Antes de este periodo, la muerte no es tema, ni merece la atención de la reflexión teológica en Israel, menos aún, no existe una teología del martirio o una valoración propia del suicidio o del heroísmo. Estos son fenómenos que se desarrollan en Grecia e Israel posterior al siglo $\mathrm{V}$ a.C. como lo señala M. Hengel, no hay en la tradición judía una "real report of a prophetic martyrdom far less any hints of a Theology of martyrdom"s. En cambio en opinión de este mismo autor, en el mundo helenístico, expresiones como "morir por", "entregarse a sí mismo" son fórmulas estereotipadas durante esta época. Subrayemos aunque sea de paso, la diferente cosmovisión en la que se enmarca nuestra comprensión del martirio de aquella época. En este sentido James Tabor señala: "in Western Antiquity the problem of voluntary Death was conceived of altogether differently

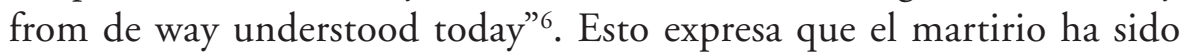
concebido no a partir de una reflexión sistemática, sino a partir de relatos míticos y metáforas que evolucionaron desde una forma histórica a otra, diversas, variables, y que configuraron la entrega voluntaria de la

\section{J. Sobrino, La fe en Jesucristo, 33.}

5 M. Hengel, The Atonement. The Origins of the doctrine in the New Testament (Wipf \&Stock Publishers, Oregon, 1981) 8.

6 A. Droge \& J. TAвor, A Noble Death. Suicide \& Martyrdom among Christians and Jews Antiquity (Harpers San Francisco, New York, 1992) 3. 
vida por los otros. Como sea el caso, las figuras del héroe o del mártir que muere por la ciudad, la ley o el pueblo, tanto en el caso griego como judío -en el caso que lo hubiesen-, se constituyen, por tanto, como una determinada forma histórica, estética, que adquiere la entrega de la propia vida que se desarrolla en este periodo ${ }^{7}$.

\subsection{Propuesta}

Nuestra hipótesis de trabajo, es la existencia de un imaginario del martirio en la apocalíptica judía, que integra fundamentalmente dos momentos: una situación de persecución, asesinato o marginación y otra, de la promesa de una exaltación a los cielos. Nosotros vamos a estudiar este imaginario mediante la pesquisa de dos metáforas: una, el ascenso del testigo al cielo, entendido como arrebato al cielo o como entronización; y la otra, la metáfora de la muerte violenta, o de la sangre derramada. Estas dos metáforas expresan el tema político-religioso de la justicia interhumana que busca la trascendencia del eschaton. En otras palabras, para ambas metáforas el tema político-religioso de la justicia se vuelve metáfora e imagen que postula las promesas escatológicas.

A partir de la configuración histórico-política de la muerte violenta del inocente de grupos marginales entendida como entrega por la Ley, por el pueblo o por Dios, y su posterior exaltación, el artículo pretende en primer lugar, fundamentar que dicho imaginario del martirio y su posterior ascenso al cielo está vinculada a grupos apocalípticos que luchan y reflexiona acerca de la justicia de Dios, descrita con recurso al mito y a estas dos metáforas. Si el mártir es arrebatado al cielo no lo es en función de separarlo de la tierra sino con el fin de legitimar una contraideología político-religiosa al poder sacrificial que requiere de víctimas, que persigue y mata; segundo, nuestra reflexión entregará datos de la elaboración de este imaginario del martirio propiamente judía que surge al regreso del destierro como momento fundacional de una nueva época, que acontece en movimientos vinculados a la apocalíptica; caracterizado fundamentalmente como una interpretación causal y escatológica de la muerte a causa de la justicia de Dios, que se expresa como sentido o racionalidad de dar la vida por la justicia divina en cuanto realidad político-religiosa.

\footnotetext{
M. Hengel, The Atonement, 3.
} 


\subsection{Estética y apocalíptica}

Pero en vista de desarrollar nuestra temática, necesitamos explicitar la relación entre estética y apocalíptica. Esta última, no se reduce solo a Israel sino que afecta a todo el Medio Oriente. Ella es un pensamiento epocal ya que significó una transformación de la racionalidad presente en todo el medio Oriente. Por tanto, es conveniente subrayar que no se trata del desarrollo de un tema bíblico meramente, sino que refleja un cambio epocal como bien lo ha visto A. Strobel ${ }^{8}$. La experiencia del destierro babilónico, el proceso de desmitologización e introducción de la racionalidad de la filosofía griega reflejan una transformación cultural de grandes proporciones. Dicha transformación está expresada por un lado por el ingreso de la episteme en la explicación del mundo, por una integración de una nueva ciencia que estudia las leyes naturales; y, finalmente, en una teúrgia que entra en diálogo con el mito y las fuerzas sobrenaturales. En este contexto mundial, respecto de la apocalíptica podemos decir:

a) La apocalíptica es un pensamiento estético, en palabras de P. Hanson "mythopoesis thought" en cuanto enigma expuesto reformula históricamente relatos, temas e instituciones del pasado; las antiguas metáforas son reformuladas a la luz de las nuevas situaciones y de una cosmovisión escatológica; pero además en relación a la aporía de la muerte y sufrimiento del justo, problema irresuelto durante el pre-destierro elabora y adopta, durante el post-destierro, conjuntos imaginarios de diverso origen cultural e ideológico. Ahora, la muerte y martirio del justo, es pensado metafóricamente, en el sentido que ser pobre, o morir por Dios es comprendido como una señal de una crisis de proporciones cósmicas que ha comenzado; padecer la persecución y ser escarnecidos son valorados de acuerdo a una nueva cosmovisión, según la cual estos son signos del triunfo de la justicia divina.

b) Esta experiencia de la muerte y martirio del justo está acrisolada con arreglo a la imaginación del eschaton. En este sentido, la apocalíptica piensa de manera mito-poiéticamente los temas de la justicia y del fin

\footnotetext{
8 A. Strobel, Kerygma und apocalyptic. Ein religionsgeschichtlicher und theologischer Beitrag zur Christus frage (Vandenhoeck \& Ruprecht, Göttingen, 1967) 131.

9 P. Hanson, "Rebellion in Heaven, Azazel and Euhemeristic Heroes in 1 Enoch 6-11”, en Journal of Biblical Literature 96/2 (1977) 202-204.
} 
de la historia. Por consiguiente la apocalíptica no tan solo representa una corriente caracterizada por determinados temas o contenidos, sino que representa una apuesta epistemológica, a saber, una epistemología de la metáfora, en vista de estimular y pensar el triunfo de la justicia divina.

c) Esta epistemología apocalíptica desarrolló, por medio de la imaginación, una estética con un alto grado de negatividad que nosotros hemos desarrollado en otra parte en relación al principio de ignoran$c i a^{10}$ y que es posible rastrear en la profunda transformación que se produce en la valoración de la muerte por Dios. Podemos decir que en textos apocalípticos la valoración positiva de la pobreza, así como el padecimiento por Dios están integrados dentro del momento negativo de la imaginación escatológica. La negatividad, según esto, no se reduce a la mentada reserva escatológica, ni la sustracción del deseo creyente a la amplitud de la promesa. La negatividad es entendida como praxis, proceso de metaforización que atraviesa la realidad de pobreza y martirio durante el post-exilio.

d) A diferencia de textos pertenecientes al mundo helenista ${ }^{11}$, la muerte voluntaria es entendida en el mundo bíblico, en relación al juicio de

10 C. Carbullanca, "La ignorancia en el evangelio de Marcos. Un acercamiento desde la literatura de Qumrán a la teoría de las parábolas", en Theológica Xaveriana 168 (2009)331-358.

11 J. Buckhardt, Historia de la cultura griega. II (Editorial Iberia, España, 1964). Para el mundo de la antigüedad la muerte es entendido como un poder o reino al cual se pertenece; en Grecia y posterior al siglo V a.C., al desarrollarse la medicina hipocrática, la comprensión mítica de la muerte cede su espacio a otra de carácter más racionalista fundado en causas naturales; en relación a la muerte de niños, se afirma que en la antigüedad existe la costumbre de dar muerte a niños deformes y pobres "los pobres no crían a sus hijos por la preocupación de que pudieran llevar una vida más miserable de lo que es justo, en servidumbre, sin educación, sin participación en lo bello"(De amore prolis,5). En relación a la muerte voluntaria, existe una serie de motivos comunes y aceptados de suicidio tales como la esclavitud, las enfermedades incurables o la vejez (República II, 407d; Consol, Ad Apolón 15); el suicidio por vejez o por hambre (Quint.Inst 8.5.23) así como se consideraba a la esclavitud peor que la muerte como se puede ver en Eurípides "una cosa te digo: no te entregues vivo y voluntario a servidumbre mientras puedas morir libremente" (Arquelao, frg.28). Según esto, para el vencido todavía queda una opción: la muerte noble (Diodoro XII,|29). Pero en el terreno bélico nos encontramos con distinciones sobre el derecho al suicidio. Cleomenes de Esparta propugna una muerte digna ( $\epsilon \dot{\theta} \theta \alpha \nu \alpha \sigma \alpha \iota)$ "no está justificado en el caso de huida, sí cuando se trata de un acto político; no se vive ni 
Dios, es decir como modo de ser del Dios de la Alianza y no en cuanto virtud del individuo. En efecto, para ambas culturas, la justicia está vinculada a la polis, pero en un caso es la virtud del ciudadano en cambio en la otra es la característica de Dios. De tal manera que la cuestión de la alta valoración de los sufrimientos, de la persecución a causa de Dios es entendida en el marco de una cosmovisión del triunfo de la justicia de Dios. Por tanto, la integración de la muerte en la acción política no apunta ciertamente a una teología que esté interesada en la eficacia política coyuntural, sino a una estética teológica en cuanto praxis que integra la pasión como momento interno del triunfo de la justicia en el mundo.

\subsection{El regreso al mito y la metáfora}

Jon Sobrino postula "hay que volver a la apocalíptica... su esperanza versa en directo sobre la justicia, no simplemente sobre la supervivencia; sus sujetos primarios son las víctimas, no simplemente los seres humanos"12. Este regreso a la apocalíptica es concomitante con el regreso al mito y la metáfora tal como ha acontecido durante el siglo pasado. Ciertamente, este redescubrimiento del mito y la metáfora lo encontramos asumido tanto en la Teología de la Esperanza como en la Teología de la Liberación, al rescatar el paradigma bíblico de la promesa, el mito del Éxodo y la categoría de liberación. Esto tiene como postulado la sincronización entre mitemas presentes en los relatos míticos del pasado y determinadas estructuras político-culturales contemporáneas, esto es, la constatación de una correlación, una 'simetría', entre el mundo mítico, transmitido a través de sueños, relatos religiosos o legendarios y el mundo objetivo secular.

Es indudable la emergencia de la metáfora, tanto en el ámbito del inconsciente personal y colectivo así como en el político-utópico durante el siglo pasado. El siglo XX se ha caracterizado por el esfuerzo teórico por desentrañar el logos metafórico inconsciente o utópico mediante

se muere para uno mismo" (Polibio XXX, 7.8). En el ámbito semita, encontramos una serie de hechos fatales relatados por Flavio Josefo que nos informan de la muerte particular o social, de suicidios religiosos como los de $2 \mathrm{Mac} 7$ o el suicidio masivo en Masada de un grupo de judíos zelotes ante la inminente caída de las legiones romanas en el año 70.

12 J. Sobrino, La fe en Jesucristo, 33. 
una hermenéutica de la sospecha que haga operativa una terapéutica social o personal. Nos parece que una Teología de la Liberación es una teología que tiene su "Sitz im Tode" en el martirio en Latinoamérica ${ }^{13}$ como su "más radical lugar hermenéutico" (ibídem). En este sentido es importante atender que el interés fundamental que traspasa toda la apocalíptica judía y cristiana es el anuncio del juicio de Dios en la creación. Todos los conjuntos imaginarios y metafóricos que acompañan este movimiento está dominado por la convicción del triunfo definitivo de Dios sobre la impiedad y violencia que domina y esclaviza la creación. Por tanto, una Teología de la liberación que asume el regreso a la apocalíptica se vuelve una teología que reflexiona desde el martirio sobre la justicia escatológica de Dios en un contexto en que la creación está dominada por un proyecto irracional, de opresión del hombre por el hombre, y de una explotación indiscriminada de los recursos naturales.

\section{LOS IMAGINARIOS DEL MARTIRIO Y LA JUSTICIA}

El motivo de la muerte voluntaria y su relación con la sangre inocente derramada alcanza a un amplio material narrativo en la literatura bíblica. De particular importancia en este sentido representan las reformulaciones del Levítico que se realizan al regreso del destierro; por otro lado, la cuestión del homicidio del inocente y la necesidad del sacrificio de reparación y del pecado, vinculado a la cuestión del sacrificio expiatorio representan un momento importante dentro de la cuestión de la expiación sacrificial como proyecto social que expía la violencia en la sociedad post-exílica judía. La vinculación de la sangre como sede de la vida está comprendida en el horizonte del tabú religioso y del contagio de la violencia homicida, y sitúa los relatos acerca del derramamiento de sangre dentro de la esfera mítica de la narración.

La tradición enóquica representa una teodicea que entiende el sufrimiento y la muerte de los justos a causa del pecado introducido por los Vigilantes. En este contexto, la sangre derramada del inocente aparece como un motivo mítico por antonomasia, vinculado al problema de la justicia divina y comprende la muerte violenta como una violación de un orden sagrado en donde la libertad del hombre queda en suspenso.

13 Cf. J. Sobrino, Mysterium Lyberationis. Conceptos fundamentales de la Teología de la Liberación. Tomo I (Trotta, Madrid, 1990) 10. 


\subsection{El arrebato y martirio en el Libro de los Vigilantes}

El regreso del exilio representa en términos de René Girard una 'crisis sacrificial' entre dos tipos de judaísmos. El cuarto Cántico del siervo de Yahvéh representa uno de los primeros antecedentes de un paradigma mítico acerca de una sociedad que asume la responsabilidad de la entrega de la propia vida como medio para dar fin a la violencia fratricida. En cambio el proyecto de reconstrucción del judaísmo sadoquita, presenta todavía un proyecto político-religioso fundado en un sistema sacrificial. Al parecer, el judaísmo enóquico, representa un paradigma político-religioso que muestra puntos de contacto con aquel que expresa el paradigma del cuarto Cántico del siervo. El proyecto enóquico expresa un alto grado de negatividad utópica, anuncia a los elegidos la utopía de la justicia que les promete paz y protección; sobre ellos se manifestará la misericordia, serán todos de Dios... se "manifestará a ellos la luz" $(1,8)$; a donde se promete a los justos un nombre nuevo $(5,6)$; citando el salmo 37 señala que los "elegidos heredarán la tierra" $(5,6.7)$; "se revelará a los elegidos la sabiduría" $(5,8)$; "ellos vivirán" $(5,8)$. Dicha negatividad funciona como dispositivo que exhorta a la fe, a perseverar en la prueba. Habrá un incremento tanto para impíos como justos: "en el iluminado, habrá luz; y en el hombre sabio, inteligencia... todos los días de su vida, crecerán en paz".

En este contexto, la primera metáfora del arrebato, que encontramos en 1 Enoch 12, 1 que dice: "antes de estas cosas Enoch fue arrebatado y

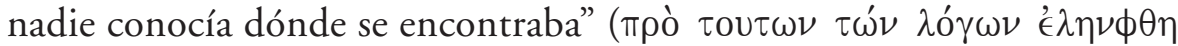

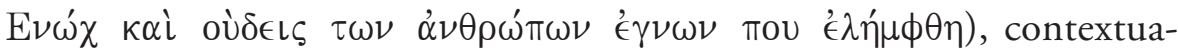
liza la sección 1, 2-5, 9 que es un oráculo del juicio, en donde Enoch realiza una prognosis de los futuros eventos escatológicos y presenta a este como un justo ( $\delta$ ík $\alpha\llcorner\circ \zeta)(1,1)$; un justo que escribe un testimonio

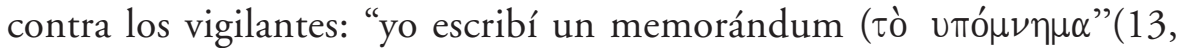
4); la sección está dominada por la idea de la justicia de Dios, la obra del

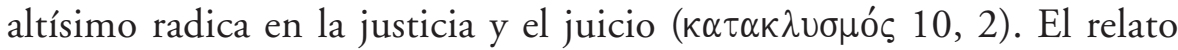
comenta que Enoch asciende sucesivamente al "cielo de los cielo"" ${ }^{14}$ y al más elevado de todos: a la presencia del trono de Dios (1Enoch 14,9) en donde está de pie delante de la gloria de Yahvéh. Esto refleja no tan solo una ideología estratificada de los cielos, o de la tierra, sino que la metáfora del arrebato se mueve dentro de una metafórica espacial en la cual

$14(1,4 ; 14,9.25 ; 17,1-4)$. 
la realidad está ideológicamente entendida en términos jerárquicos ${ }^{15}$. Notemos lo siguiente. Si tanto la teología sadoquita como el judaísmo enóquico aceptan la existencia de un sinfín de seres creados por Dios (ver Gen 1, 1-24): serafines, ángeles, vigilantes, arcángeles, ministros, y otros seres espirituales, luego el hombre y las demás creaturas que conformaban el cosmos. No obstante esto, este esquema imaginario, mítico-ideológico, es considerado de un modo distinto en corrientes como las que representa 1Enoch 6, 1-11, 2 y Ant Biblicas 19, 16, ya que dicho ascenso presupone una mediación alternativa a la del sistema religioso sacrificial. Para estos textos no es el sumo sacerdote quien es mediación entre los hombres y Dios sino el visionario y mártir. Por tanto estamos ante una valoración distinta dentro de este imaginario de la estratificación de seres, en la cual el sufrimiento, padecimiento y muerte del siervo de Dios que muestra el cuarto Cántico de Yahvéh, es considerada paradójicamente con mayor valor a la mediación del sumo sacerdote o al de los mismos ángeles ${ }^{16}$. Esta inversión cósmica también se aprecia en el texto de 1Enoch 6, 1-15, 2. Así como los ángeles caídos descienden, Enoch, el hombre justo es arrebatado y llamado justo. No es casual este movimiento descendente y ascendente. El arrebato es una metáfora del imaginario de la inversión cósmica que apunta y está en función de legitimar e instaurar la justicia divina. Es un hombre el que asciende y está por sobre los ángeles; es un hombre el que escribe un testimonio contra los vigilantes: "yo escribí un memorándum" $(13,4)$; es un hombre el que relata estos hechos ante Dios $(13,4)$; el que es llamado "escriba de verdad" debido a su misión de ser testigo de los hechos de los hombres.

Una segunda metáfora, la encontramos en el texto de 1Enoch 6-11, clasificada según Paul Hanson ${ }^{17}$ como relato explicativo, el cual utiliza temas de Gén 4-10 interpretados desde una escatología apocalíptica. En este texto, posiblemente escrito anterior al 200 a. C. ${ }^{18}$ como reacción

15 G. Boccaccini, I Giudaismi del Secondo Tempio. Da Ezejiele a Daniele (Morcelliana, Brescia, 2008) 91-93.

16 R. Baucкham, “The Martyrdom of Enoch and Elijah: Jewish or Christian”, en Jorunal of Biblical Literature, 3/95, (1976) 447-458.

17 P. Hanson, "Rebellion in Heaven, Azazel and Euhemeristic Heroes in 1 Enoch 6-11", en Journal of Biblical Literature 96/2(1977) 197.

18 G. Boccaccini, "É Daniele un testo apocalittico? Una ridefinizione del pensiero del Libro de Daniele in rapporto al Libro del Sogni e all'Apocalittica”, en Henoch IX (1987) 4. 
a la introducción de los dioses helénicos ${ }^{19} \mathrm{y}$ de modo paralelo al relato de Génesis, se caracteriza el diluvio como imagen del juicio en cuanto ruptura y caos del orden del cosmos creado por Dios. El pecado de los ángeles es caracterizado como un caos cósmico, entitativo, epistemológico y ético ${ }^{20}$. Hanson confirma los paralelos en $7,5 \mathrm{c}$ referido a las prácticas de beber sangre prohibida en Gén 9, 4 y "con el grito el cual sube a los cielos" en 8, 4 parafraseando libremente las palabras de Gén 4, 10. El mito expresa que, el fruto de esta nueva creación está marcado por el caos. Los hombres no pudieron sustentar a hijos nacidos de los Vigilantes; estos hijos, los gigantes "se volvieron contra ellos y devoraron

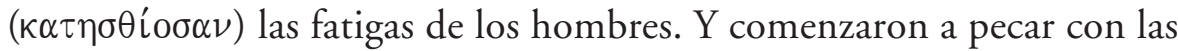
aves, los animales y reptiles y peces y unos de otros devoraron las carnes y bebieron la sangre". Esto mismo, es lo presentado en 4Q202 col. II, 23 "los gigantes planearon matar a los hombres y consumir a ellos y comenzaron a pecar...”. En efecto el paralelo de Gén 4, 10 y 1 Enoch 8, 4 está en relación a la sangre de Abel que clama al cielo, pero en 1 Enoch está en relación a la sangre de los justos derramada y al incremento de la injusticia.

“...y un grito subió a los cielos. Miguel, Sariel, Rafael y Gabriel bajaron del santuario de los cielos a la tierra y vieron mucha sangre derramada sobre la tierra y toda la tierra estaba llena con maldad la violencia perpetrada..."

En corrientes apocalípticas la metafórica del grito que sube al cielo, de la sangre derramada y de la figura de Abel pertenece a un mismo imaginario relativo a la justicia de Dios interpretado escatológicamente. Ahora bien, el paralelo funciona con la figura de Abel, pero no con la de Caín. A diferencia del relato del Génesis, en donde el responsable de la muerte de Abel es Caín, en el relato de 1 Enoch la responsabilidad es derivada y compartida, a entidades espirituales e históricas como los Vigilantes y los impíos. Observamos una diferencia en la demonología apocalíptica y la sapiencial. El Satán de Job tiene menor responsabilidad moral que la que apreciamos en el relato de 1 Enoch. La cuestión de la

19 G. Nickelsburg; J. Vanderkam, 1Enoch. A New Translation (Fortress Press, Minneapolis, 2004) 2.

20 D. Suter, "Theodicy and the problem if the Intimate Enemy", en G. Boccaccini (dir.), Enoch and Qumran Origins. New Light on a Forgotten Connection (W. Eerdmans Publishing, Cambridge, 2005) 232. 
justicia en 1 Enoch no solo alcanza con esto a la realización del eschaton en cuanto fin del sufrimiento histórico del justo sino también atiende a comprender la imagen de Dios en un mundo irredento. Comparativamente hablando, la preocupación por la justicia divina de 1 Enoch en relación a la que presenta el libro de Job y que se constata en 1 Enoch 9, 11 tiene una hondura política y religiosa radical que aquel libro no alcanza a vislumbrar: "tú todo lo sabes antes de que acontezca y tú ves estas cosas y las permites y no nos dices nada, qué debemos hacer con

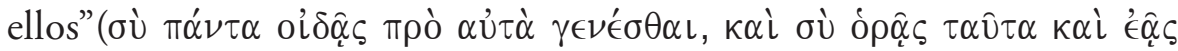

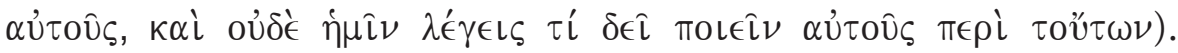
Ciertamente, la demonología de 1 Enoch salva la bondad de la creación derivando el mal y el pecado de entidades autónomas de Dios dando un paso para conjugar el problema de la libertad y la historia con las del eschaton.

\section{Resumen teológico}

Si los ángeles caídos descienden, Enoch, el hombre justo es arrebatado y llamado justo. Este movimiento descendente y ascendente refleja un modelo imaginario de inversión cósmica que apunta y está en función de legitimar e instaurar la justicia divina. El testigo (mártir) es un hombre no un ángel, que es arrebatado y que no solo convive con ángeles en la esfera divina y que tiene funciones escatológicas como escriba, es portavoz de la sangre derramada por los impíos en el juicio final, sino que además ingresa en la esfera de los principales colaboradores del altísimo; esta diferencia entre ángel y testigo posee gran relevancia. En la Biblia no existe pasaje alguno en donde se mencione a un ángel como testigo, pareciera ser que no le corresponde ser testigo, y que es inherente al hombre ser testigo, no así a un ángel. Enoch es testigo enviado escatológico para amonestar a los ángeles caídos; es decir posee un rol cósmico en los eventos escatológicos. Enoch es un hombre que es arrebatado no solo porque "caminó con Yahvéh" como lo señala Gén 5, 24, su arrebato no mira a su historia pasada, sino que se presenta en función de su misión escatológica: comunicar el dictamen divino a los ángeles caídos y ser testigo en el juicio. El imaginario de la sangre derramada metaforiza la figura de Abel, el protomártir en la tradición judeo-cristiana en la cual la propia sangre, como ser viviente es la que clama al cielo por justicia. Enoch es testigo ante Yahvéh de la sangre derramada de otros hasta el final de los tiempos. Pero Enoch no es alguien aparte de los justos, sino 
que es uno entre otros justos a quienes las metaforización del eschaton acontece negativamente: se les promete la paz, la seguridad, la vida, la luz y que heredarán la tierra.

\subsection{El arrebato y martirio en Jubileos}

De la misma manera que 1 Enoch, en el libro de los Jubileos, que recibe el nombre 'pequeño Génesis', sigue este mismo modelo, pero a diferencia de aquel, es Moisés y no Enoch el que recibe la prognosis de los eventos escatológicos. El capítulo 1, muestra la metáfora del ascenso, está potenciada por medio de una prognosis al señalar: "subió Moisés al monte del Señor y su gloria se asentó sobre el Sinaî” (1, 2). En esta prognosis introductoria, tiene un carácter metafórico, pues advierte al visionario sobre el martirio: "enviaré a ellos testigos para exhortarlos, pero no escucharán incluso matarán. Perseguirán a los que estudien la Ley, la abolirán”; en los textos de Qumrán, la copia de Jubileos, el texto de 4Q216 trae el término técnico עדים que significa, testigos. Los relatos de ascenso a los cielos, apertura del cielo responden a este imaginario al mover el pensamiento del lector hacia adelante; se trata de la apertura desde el presente hacia un sentido nuevo: la necesidad de sufrir o morir por, sabiendo que este sufrimiento es necesidad y medio de otro momento de exaltación final. Esta relación metafórica entre arrebato al cielo y prognosis en función de un sentido futuro es importante y se repetirá en sucesivos relatos, en donde se requiere legitimar y exhortar al creyente a que comprenda la necesidad del sufrir y morir por Dios como un momento positivo de su camino a la exaltación ${ }^{21}$. Vemos aquí el germen de la transformación en la valoración escatológica del sufrimiento y la persecución del justo en la época final de la historia.

A partir del capítulo 2 narra la creación. El relato se mueve en el horizonte de un imaginario animista de la sangre como fuente de la vida. La causa del derramamiento de sangre radica en la introducción del pecado de los Vigilantes aunque introduce la responsabilidad humana, lo cual ha llevado a que Yahvéh envíe el Diluvio, Noé advierte a sus hijos en consonancia con Lev 17, 33s y Dt 12, 32: "Temo por vosotros, que tras mi muerte derramaréis sangre humana en la tierra y desapareceréis", y más adelante "todo el que derrame sangre de cualquier hombre y todo el que coma sangre de cualquier carne desaparecerá de la tierra" $(7,28)$ y

${ }_{21}$ (ver AscIs 1, 11; 2, 33; Mc 9, 11-13). 
en relación al homicidio, dice Jub 7, 33: "la tierra no se ha de purificar de la sangre que se derrame sobre ella. Solo se purificará para siempre con la sangre del que la derramó" (Núm 35, 33). En estas normativas asumidas por la literatura apócrifa constatamos la importancia del tema del derramamiento de sangre inocente en el cual se constata el tabú religioso fundado en la creencia que la vida, es don de Dios y que yace en la sangre del hombre. En el derramamiento de sangre hay una agresión no solo a la víctima sino al principio divino de la vida que tiene sede en la sangre del hombre. El carácter mágico-animista de esta imagen se encuentra graficado en Jub 21, 14-16 (4Q219 col. II, 17) "no comas sangre porque la sangre es vida: no comas sangre". Estas leyes están recogidas en el paradigma mítico de Abel y la interpretación de este motivo en TestAbraham 7, 13 lo comprueba, en el sentido que el mito de la sangre derramada funcionó como criterio escatológico de la salvación: “...es el hijo del primer hombre creado, aquel que es llamado Abel... se sentó para juzgar a toda la creación y para examinar a justos y pecadores, porque Dios ha dicho: no soy yo quien juzgará el mundo, sino cada hombre será juzgado por otro hombre". Resulta interesante que el imaginario de la sangre derramada, expresada en el relato mítico de Abel se transforma en principio y esperanza en contra de la injusticia. Por otro lado, esta insistencia en leyes cultuales y la misma figura de Moisés en el libro de los Jubileos remite a una tradición levítica contraria a leyes cultuales del culto jerosolimitano. Esto mismo se comprueba al presentar la figura de Enoch que además de la función de testigo, aparece con la de sacerdote celeste, hace oraciones, ofrendas, intercede, etc. (4, 25). Según esta interpretación legal, el culto no tiene justificación por sí misma sino que remite a realizar la justicia humana efectivamente.

En cuanto testigo, Enoch es mártir entre otros mártires lo cual no está presente Gén 5, 24; de acuerdo a esto la finalidad del imaginario del arrebatamiento de Enoch posee una función escatológica: Enoch es arrebatado u oculto en el "jardín del Edén para gloria y honor" $(4,23)$, tiene la misión de ser testigo del altísimo (1Enoch 12, 4). Él mismo será una señal y para dar testimonio contra los hijos de los hombres en el día del juicio (Jub 4, 24). La metáfora de ser señal para otros expresa el carácter paradigmático que adquiere la figura de Enoch. En efecto, este es el primero de muchos mártires (Jub 4, 18) que tiene como misión ser enviados a la tierra para dar testimonio así, p.e., Jub 1, 12 "enviaré a ellos testigos para exhortarlos, pero no escucharán incluso matarán”. La 
metáfora del arrebato está en función de la prognosis de Enoch que integra la muerte de los testigos, como hemos ya dicho, la prognosis postula un sentido salvifico del sufrimiento del justo. Pero además, vemos aquí una democratización de la misión del testigo, ya no tan solo está referido a dar testimonio contra los Vigilantes sino que también es enviado a los hombres para exhortarlos, aunque no los escuchen.

\section{Resumen teológico}

La metáfora de la ascensión de Moisés al Sinaí y la prognosis de los hechos futuros hacen al lector buscar el sentido positivo, necesario, del martirio dentro de un contexto más amplio de la historia universal guiada por Dios. En el relato de Jubileos asume pacíficamente la reflexión de 1 Enoch, en donde la figura de Enoch adquiere caracteres sacerdotales en el cielo; pero además pareciera que el sentido de la historia y la libertad humana comienza a desarrollarse en el concepto de muerte voluntaria, así p.e., en Jub 7, 33. La interpretación de este motivo en TestAbraham 7, 13 refleja que el martirio fue interpretado dentro de un esquema escatológico de la salvación: en donde son las víctimas las que juzgan a los hombres "...es el hijo del primer hombre creado, aquel que es llamado Abel... se sentó para juzgar a toda la creación y para examinar a justos y pecadores, porque Dios ha dicho: no soy yo quien juzgará el mundo, sino cada hombre será juzgado por otro hombre". Esto refleja nuevamente una nueva consideración del lugar teológico de las víctimas de persecución, el mismo Dios se exime del juicio final, derivándolo a Abel, la víctima, como juez escatológico de la creación.

\subsection{La sangre del justo en las Parábolas de Enoch}

Es muy debatida la fecha de redacción de las Parábolas de Enoch (LP) pero de acuerdo a los últimos estudios el Libro de las parábolas (cap. 37-71) está datado por G. Bampfylde antes del 50 a. C ${ }^{22}$. En relación a la primera metáfora, las Parábolas de Enoch relacionan el arrebato al cielo con otra metáfora de la entronización en los cielos ${ }^{23}$. En el texto de

22 G. Bampfynde, "The similitudes of Enoch. Historical allusions", en Journal of Semitic of Jews Studies XV (1984) 9-31.

23 C. Carbullanca N., "El mito de la exaltación del hombre. Antecedentes de la cristología del Hijo del hombre joanico", en Anales de Teología de la Universidad Católica de la Santísima Concepción 2/13 (2011) 307-334. 
1Enoch 12, 1, la traducción de Piñero (1984, 49 nota 1) dice "Antes de estos sucesos, Henoc estaba oculto, y ninguno de los hijos de los hombres, sabía dónde se escondía, dónde estaba, ni qué era de él”. Esta es la versión del manuscrito Etíope; en cambio el manuscrito griego traduce 'ser arrebatado'. Esta equivalencia entre 'ser arrebatado' y 'ser oculto' es importante mantenerla pues se refleja también en 1Enoch 61, 7: "pues desde el principio estuvo oculto el Hijo del hombre" así como en algunos textos neotestamentarios ${ }^{24}$. Así también, el relato de 1 Enoch 48, 6 y 61, 7 guarda relación con el texto de Dt Is 49, 2 "él me ocultó a la sombra de su mano". Es pues probable que el imaginario de no ser hallado, estar oculto o ser arrebatado pertenezca a este mismo imaginario. Pero más allá de estas alusiones legitimadoras del que es arrebatado al cielo, nos interesa recalcar que la entronización muestra una radicalización de la metáfora del arrebato, el raptado a los cielos ya no solo es un testigo ante Dios, sino que ahora se sienta en los cielos en un trono de Gloria para juzgar a Israel. Dicha metáfora está en relación a la misteriosa figura del Hijo del hombre escondido o arrebatado desde antes de la creación. Este personaje recibe diversos títulos: Elegido, Justo e Hijo del hombre. En el texto de 1Enoch 51, 4 señala: "En esos días el Elegido se sentará sobre mi trono... y todos se convertirán en ángeles en el cielo". En opinión de J. Jeremías estamos en presencia de una cita de Dt-Is 42, 1 en donde se menciona al siervo de Yahvéh como el Elegido ${ }^{25}$. Esta relación es notable pues establece un vínculo entre la creencia en la exaltación del Elegido y la transformación causal de los elegidos en ángeles semejante a la que encontramos en textos como 1 Cor 15, 23-26. La entronización del Elegido da inicio al juicio sobre las naciones, así en 1 Enoch 61, 8 "el señor de los espíritus puso al Elegido sobre el trono de su gloria y juzgará a todas las naciones" y 62, 5 “...cuando vean aquel Hijo del hombre sentado en su trono glorioso". En esta tradición enóquica la figura del juez divino ya no es como en 1 Enoch 14, la Gloria de Yahvéh, sino el mismo Enoch que ha llegado a ser "el Elegido" y el "Hijo del hombre".

La segunda metáfora, la experiencia del martirio y el horizonte de la justicia está presente en las Parábolas de Enoch; en los textos de 1Enoch 38,$2 ; 47,1$ se dice "se habrá elevado la oración de los justos y la sangre del justo desde la tierra ante el Señor de los espíritus"; tanto la expresión

24 (ver Jn 1,3 1; 7, 10; 12, 36; Hch 1, 9).

25 W. Zimmerli; J. Jeremias, The servant of God (SCM Press, London, $\left.{ }^{2} 1965\right) 60$. 
de "la sangre del Justo" como "la oración de los justos" $(47,1)$ remiten al tema de la sangre intercesora del justo. Señalemos algunos elementos importantes de este texto antológico. Primero, es muy probable que la denominación del Justo para el Hijo del hombre y Elegido refleje un uso corporativo de dicha denominación. Segundo, de acuerdo a esto, son las víctimas y su representante el Hijo del hombre quienes juzgan a todas las naciones. Tercero, en esta tradición se considera que la metáfora de la sangre derramada se identifica con el clamor del justo que sube al cielo no solo como víctima sino también como juez, en el drama cósmico final de la justicia de Dios. Si consideramos que en 1Enoch 51, 4 existe una relación causal entre la entronización del Justo y la transformación de los justos en ángeles; si la misma sangre de estos es la oración que sube al cielo, entonces estamos ante una interpretación soteriológica de la muerte del justo ante Dios; finalmente, es importante expresar de acuerdo al uso del salmo 37 en 1 Enoch la identificación ahora domi-

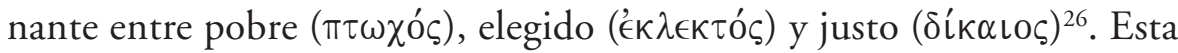
identificación representa la señalada inversión escatológica, o en palabras de James Tabor 'cosmic reversal ${ }^{27}$ de los destinatarios del eschaton lo cual es "heart of apocalyptic eschatology", que afirma que la bendición divina es para los humildes, hambrientos, como lo señala Lc 1,51-53 “dispersó a los soberbios de corazón. Derribó del trono a los poderosos y exaltó a los humildes. A los hambrientos colma de bienes y a los ricos los despide vacíos". Y por tanto expresa que su propia condición de humildes, escarnecidos, perseguidos o morir por Dios se trasforma en el lugar de la salvación, tema que caracteriza las metáforas propias de estos grupos.

Esta relación entre pobre y justo resulta de la mayor significación pues el texto en 1Enoch 47,2 identifica la sangre derramada con la sangre de los justos: "la sangre de los justos que fue derramada". La identificación entre pobre y justo pretende metaforizar a los sujetos del eschaton, no es casualidad que diversos grupos judíos se apropian de dicha identificación durante este periodo (esenios, judíos de la diáspora). En este sentido este texto de las Parábolas se aproxima a las bienaventuranzas neotestamentarias que considera sujetos de la justicia divina a los pobres

26 Durante el periodo del destierro la doctrina de la justicia y los sujetos escatológicos se concentra con el 'pueblo pobre y humilde", así p.e. en Sof 3, 12-13; Is 29, 18-19, Zac 11,11 y 13,7 .

27 A. Droge \& J. Taвor, A Noble Death, 70. 
y perseguidos. En el mismo texto continúa: "para que se haga justicia y no haya de ser eterna su paciencia [...] el corazón de los santos se llenó de alegría pues se ha cumplido el cómputo de la justicia, habia sido oída la plegaria de los justos y la sangre del inocente era reclamada ante el señor de los espiritus".

\subsection{La Epístola de Enoch}

En la sección de 1En 102-104 perteneciente a la Epístola de Enoch (92-105), datado en la segunda centuria a. C. por Nickelsburg ${ }^{28}$ dirigida a los "hijos de Enoch", es decir, a los contemporáneos del propio autor, tiene por finalidad discutir la existencia de justicia divina. Boccaccini divide la Epístola en dos partes: la proto-epístola, un escrito prequmrámico y la Epístola propiamente tal, caracterizada como un escrito post-sectario $^{29}$. Resulta interesante señalar la relación entre martirio y futura resurrección durante este periodo. A juicio de Hans Walter Wolff el influjo de Is 53,11 s es probable ${ }^{30}$. Al margen de esta cuestión, es muy probable que asistamos en este texto a un lugar común en la literatura sapiencial-apocalíptica acerca del destino del justo.

La metáfora del ascenso aparece en la Epístola de Enoch como una visión celestial $(93,2)$ referida a los justos en 1Enoch 91, $10(92,3)$ : "se levantará el justo de su sueño, se alzará la sabiduría y les será otorgada", también en 97, 5: "en esos días ascenderá la plegaria de los justos al Señor, pero a vosotros os llegarán los días de vuestro juicio". Ya hemos señalado a propósito de 1Enoch 8, 4 el cual traslada en motivo de la sangre de Abel, al grito del pueblo que sube al cielo, en la Epístola de Enoch el motivo del ascenso y la persecución de los justos están integrados, de tal manera que el tema del relato es la justificación del pueblo de los justos y la reprobación de los impíos. Por 1 Enoch 12, 1 sabemos que el visionario experimenta visiones $(14,1)$, la misma visión del trono divino y los viajes que realiza Enoch $(17,1-36,1)$ es porque ha sido previamente

28 G. Nickelsburg, Jewish Literature between the Bible and The Misnah (SCM Press, London, 1981) 150.

29 G. Boccaccini, Beyond the Essene Hypothesis. The Parting if the Ways between Qumran and Enochic Judaism (W. Eerdmans Publishing Co., Gran Rapids/ Cambridge, 1998) 131-138.

30 H.W. WolfF, Jesaja 53 im Urchristentum (TVG Brunnen Verlag, 1984) 42-45. 
arrebatado al cielo. Por tanto arrebato, viaje y visiones son concomitantes y pertenecen a un mismo campo semántico.

Para nuestro propósito la sección de 1Enoch 102-104 resulta particularmente significativa, la cual en opinión de Nickelsburg es un clímax ${ }^{31}$. En el texto de 1Enoch 102, 6 se expresa que la finalidad del relato es la justicia "cuando morís, dicen de vosotros los pecadores: 'los justos han muerto igual que nosotros: ¿de qué les han servido sus obras?’” ...La respuesta que da el libro es similar a la que encontramos en otros textos de este periodo como Sab 1, 16-5, 23 se promete la vida futura al justo sufriente: "vivirán vuestros espíritus, de los que habéis muerto en justicia" $(103,4)$, esto muestra que la condición de pobre y la desgracia de ser perseguido o asesinado por Dios han llegado a ser medio necesario para acceder a su justicia. Un paralelo esencial para nuestro objetivo lo constituye el texto de 1Enoch 103, 7-3 que luego de una larga letanía de males narrada sarcásticamente por los impíos (v. 9), que recuerda la persecución del justo de los textos de Is 52, 13s y Sab 1, 16-5, 23, en los cuales en una mirada en retrospectiva, son los pecadores y no el justo quien es el que narra los hechos:

"en los días de nuestra aflicción, sufrimos trabajos, vimos toda aflicción, soportamos muchos males, hemos sido exterminados, diezmados y hemos humillado nuestro espíritu. Hemos perecido sin que nadie nos ayude con palabras u obras; nada hemos encontrado, hemos padecido y perecido sin esperar tener vida..."

A partir del 104, 2 habla Yahvéh "Os juro justos que en el cielo os recordarán los ángeles para bien ante la gloria del grande" y continúa:

"tened esperanza, pues antes habéis sido escarnecidos con maldades y aflicciones, pero ahora brillaréis como las luminarias del cielo".

Este relato expresa la inversión escatológica que ya hemos mencionado, en la cual los que han sido escarnecidos y afligidos en esta vida se les promete los bienes escatológicos, expresado bajo la imagen del brillar como estrellas. Queda claro entonces que el imaginario de la exaltación o resurrección no es independiente del otro de la vida entregada por Dios; los textos nos presentan una relación causal, a aquellos que han sido escarnecidos con maldades y aflicciones se les promete brillar como luminarias del cielo.

31 G. Nickelsburg, Jewish Literature, 148. 


\section{Resumen teológico}

La perspectiva sigue siendo escatológica y la muerte del justo es entendida como muerte por Dios, posee un carácter soteriológico. En este sentido es importante atender al carácter causal de la promesa, que refleja a nuestro entender la inversión escatológica tan propia de la apocalíptica: "pues antes habéis sido escarnecidos, ... ahora brillareis como luminarias". Esta relación causal refleja, a nuestro entender, la comprensión que el sufrimiento y la desgracia es entendido como medio necesario y por tanto una valoración positiva de la pobreza y la muerte por Dios, lo cual representa, en germen, el concepto de martirio por Dios. La secuencia persecución-brillar como estrellas que está presente en el LP, aparece claramente en los textos de este periodo ${ }^{32}$. De acuerdo a esto, pareciera que durante este trascurso histórico, existe una integración entre la forma de morir y la promesa escatológica; la relación entre ambos aspectos es causal de tal manera que 'ser escarnecidos con maldades y aflicciones expresa un lugar teológico desde el cual el narrador afirma y estima propicia la condición de pobre y escarnecido en vista de una futura reivindicación por parte de Dios. Por otro lado, se requiere hacer notar la gran variedad de formas que adquiere esta esperanza. En diversas partes de 1 Enoch se aprecia la negatividad del eschaton invocada bajo las imágenes del brillar como estrellas, presente en 1 Enoch 1, 8 "se manifestará a ellos la luz"; concomitante con la otra, de llegar a ser como ángeles en el cielo como lo expresa 1En 51, 4: “...todos se convertirán en ángeles en el cielo". En el LP representa un testimonio significativo que deja en evidencia, la situación de martirio y humillación que sufren los justos. Esta variedad de formulaciones nos confirma a nuestro juicio el carácter estético del martirio, es decir, la "evidence for a revolutionary ideological transformation in the area of the theodicy" ${ }^{33}$. La promesa de una futura reivindicación es prometida a los justos y elegidos; no se trata en definitiva de una vida más allá de la muerte, sino en sentido estricto, del triunfo de la justicia de Dios.

32 (ver 1 Enoch 108, 6-10; Asc Moisés; Dn 12, 3).

33 D., Suter, Theodicy and the problem if the Intimate Enemy, 334. 


\subsection{Daniel 7, 11-12 y $9-12$}

El Hijo del hombre del libro de Daniel, es necesario considerarlo en relación a este contexto histórico-ideológico existente en tradiciones apocalípticas judías. El relato de Dn 7, 1-14 es un relato compuesto con elementos heterogéneos. En los vv. 1-8. 11-12 el relato muestra su sentido a través de la metafórica dialéctica de animal-hombre ${ }^{34}$. Es decir se establece una relación entre la sucesión de reinos bestiales y el reino del Hijo del hombre (כבר אנש) (v. 13). Cada bestia representa un imperio o pueblos; de manera análoga el Hijo del hombre posee también, un sentido colectivo, se trata del pueblo de los santos. La relación metafórica animal-hombre la encontramos también en el capítulo 5, en donde el rey Balthasar es transformado en bestia. Estos versículos nos dan la pragmática socio-política en la que está inserta la metáfora del arrebato en el libro de Daniel.

En los vv. 9-10. 13-14 aparece a nuestro entender la metafórica del ascenso en cuanto el texto re-interpreta el texto de 1 Enoch 14 y Ez 1, 26 presentando la descripción del trono y del Hijo del hombre. El reinado del Hijo del hombre está contrapuesto al reinado de los imperios bestiales. La figura del Hijo del hombre que viene en las nubes del cielo es alguien que viene desde lo alto. Los motivos del "contemplar" (vv. 1.7.13.15) y del "venir" (v. 13) pertenecen al campo semántico del "mártir/testigo" que narra lo que ha visto y oído en el mundo de arriba $(1 \mathrm{Jn} 1,1)$. El Hijo del hombre viene a esta historia en la cual el pueblo de los santos es dominado por imperios. A este Hijo de hombre de manera semejante al de las Parábolas de Enoch es entronizado, al darle "dominio ( $\left.{ }^{\epsilon} \xi o v \sigma i ́ \alpha\right)$, gloria $(\delta o ́ \xi \alpha)$ y reino $(\beta \alpha \sigma\llcorner\lambda \in i \alpha)$ ". La metáfora del ascenso es radicalizada en el libro de Daniel mediante la introducción de la terminología de la entronización lo mismo que en las Parábolas. Esta es predicada como futura recompensa para los justos que son perseguidos por confesar la fe judía. La secuencia del imaginario persecución-despertar/ brillar como estrellas es prometida a los mártires. En Dn 12, 2 se menciona que "serán despertados" y en v. 3, muestra la convicción de que los sabios serán elevados a una vida semejante a la de los ángeles en el cielo. La denominación "como estrellas" es una referencia a la vida de los ángeles. El ser despertados se enuncia de aquellos que "duermen en el polvo", en cam-

34 J.J., Collins, Apocalyptic Imagination. An Introduction to the Jewish Matrix of Christianity (Crosrroad-New York, 1984) 82-84. 
bio el "ser transformado en estrellas" es posible que se refiera a aquellos que los encuentre vivos durante el eschaton. Este mismo incremento de vida es entendido en 12, 3 en relación al verbo ứó $\omega$, el cual es tomado de Is 52,13 . Al respecto, es importante destacar en primer lugar el uso de Is 52,13-53, 12 que se introduce durante esta época para interpretación escatológica que se hace de la persecución por los reyes de los reinos bestiales que sufren los maskilim, p.e. en el texto de LXX Dn 11, 36 utilizado en sentido político-escatológico: "El rey hará su voluntad, se ensoberbecerá y se engrandecerá (ì $\psi \omega \theta \eta \dot{\sigma} \sigma \tau \alpha \iota)$ sobre todo Dios" y en $12,3$ "en aquel día será exaltado (ì $\psi \omega \theta \eta \dot{\sigma} \sigma \in \tau \alpha \iota)$ todo el pueblo que esté escrito en el Libro". También Dn 7, 20 tiene este sentido: "Este cuerno tenía ojos y una boca que hablaba arrogancias, y parecía ser más grande que sus compañeros". Este sentido político-escatológico está en el centro de la metáfora del arrebato y de la exaltación, el cual es fundamental para comprender su sentido en los textos neotestamentarios. El texto de la LXX Dn 12, 3 traduce מליט "liberar" del texto masorético por ư $\psi \theta \theta \dot{\sigma} \sigma \epsilon \tau \iota$ "exaltar" teniendo como sujeto al pueblo de los santos del mismo modo que encontramos en AscMoisés 10, 9. A juicio de Nickelsburg el texto de la Ascensión de Moisés es más cercano que Dn 12, 3 a la tradición de Is 52-53. Ya que este último habla de "transformación a las estrellas" en cambio el texto de AscMoisés trata de "exaltación" como el texto isaiano.

La metáfora de la sangre derramada la encontramos en las secciones de Dn 7, 21.25; 9, 1-12, 13 en Dn 7, 25 se indica que los santos "serán entregados en sus manos" de los reyes lo que describe el imaginario de Abel y el periodo de persecución que viven los maskilim. En esta sección $(9,1-12,13)$ mediante un pesher se anuncia la época de los dolores, la profecía del asesinato de un ungido de Yahvéh (Dn 9, 26): "Después de las sesenta y dos semanas se quitará la vida al Mesías". Al respecto es interesante constatar notable coincidencia durante este periodo de un ungido sufriente, así p.e. el TXII Patriarcas 18,1; TIsaías 53, 4; 4Q213b (4QAramaic Levi ${ }^{\mathrm{b}}$ ) sobre ungido escatológico y la construcción de un nuevo santuario: "y construirá el santuario de Dios que fue profanado". No es improbable, que el asesinato del ungido Onias y la profanación del templo fuesen interpretados a la luz del texto isaiano, según lo demuestra la versión griega de Dn 12, 3. El contexto de reconstrucción de un santuario escatológico es importante ya que muestra que en el siglo II a.C. se comenzó a interpretar la crisis macabea a la luz de Is 52, 13s. Esta 
atención a la persecución y martirio se percibe en el texto de LXX Dn 12,3 , donde se menciona a los sabios quienes enseñan al pueblo y sufren la persecución; se menciona la caída o muerte de algunos y el ambiente de complot que los acompañará.

\section{Resumen teológico}

La metáfora del arrebato está contextualizada político-escatológicamente, la terminología del martirio de ver y contemplar, viajar y ascender está formulada en un contexto en que existe la pretensión bestial del endiosamiento de poderes políticos mundiales. Al contrario, la venida del Hijo del hombre presupone la imagen de 1Enoch 14 y Ez 1, 26 en el cual la gloria de Yahvéh adquiere rasgos antropomórficos. La metáfora del ascenso es reemplazada mediante la introducción del término exaltar, utilizado primero políticamente en relación en reyes terrenales, así p.e., en Daniel 7, 20-21: "Este cuerno tenía ojos y una boca que hablaba arrogancias, y parecía ser más grande que sus compañeros. Yo veía que este cuerno hacía guerra contra los santos y los vencía" expresa el concepto de exaltación referido a Antíoco Epifanes, el cual persigue a los santos y los vence. Los santos son entregados en manos de los reyes. La exaltación por tanto es predicada políticamente para expresar el poder político perverso que persigue a los santos, en un segundo momento se predica como futura recompensa para los justos que son perseguidos por confesar la fe judía. La secuencia del imaginario persecución-despertar/ brillar como estrellas es prometida a los mártires. No se trata de afirmación filosófica de una vida más allá de la muerte simplemente, sino de la promesa del triunfo de la justicia en un mundo en donde hay poderosos que oprimen a los santos. En diversas partes del libro de Daniel se confirma la idea de estar frente a un imaginario del martirio ${ }^{35}$; así p.e., en Dn 3, 21-25; 6, 16-23 y en 9, 12. En este último texto se habla la muerte de un ungido. Además se introduce la terminología de la resurrección en Dn 12, 2 donde se menciona que "serán despertados" y en el v. 3, muestra la convicción de que los sabios serán elevados a una vida semejante a la de los ángeles en el cielo. El ser despertados se enuncia de aquellos que han muerto mártires de la justicia divina en este mundo.

35 Así p.e. en Dn 3, 21-25; 6, 16-23. 


\subsection{Ascensión de Moisés}

En el relato del AscMoisés 8, 1-4, datado según G. Nickelsburg durante la revuelta macabea ${ }^{36}$ encontramos también estas dos metáforas propias de este imaginario, a saber, la persecución y la posterior exaltación.

Hay que decir que el relato presenta la metáfora del arrebato en 11, 5; 8, 2 "qué lugar te recibirá... porque todo el que muere cuando viene su tiempo tiene una sepultura en la tierra. Pero tu sepultura se extiende desde el este al oeste y desde el norte al extremo del sur. El entero mundo es tu sepultura"; también 12, 5-6 texto que estando incompleto, expresa la metáfora para referirse a Moisés que es quien habla a Joshua en ese momento: "He aquí (que yo) seré tomado lejos. El señor me ha constituido por ellos y por sus pecados, que yo debo orar y suplicar por ellos". El motivo mítico del desconocimiento del lugar de la sepultura de Moisés responde a la metáfora del arrebato ya que se cree (como en el caso de Elías y Melquisedec) la ignorancia del origen y del fin de sus días es signo de su carácter divino. También la metáfora es utilizada mediante el término "exaltar", aplicado como en Dn 12, 3, al pueblo de Israel; en este caso la metáfora de la exaltación está vinculada a la transformación en estrellas, así p.e., AscMoisés 10, 9 "et altavit te Deus, et faciet te herere caelo stellarum" “...y Dios te exaltará (Israel) y hará vivir en las estrellas del cielo". Taxo tiene semejanzas con el profeta Elías, Taxo lo mismo que este ( 1 Mc 2,58$)$ es perseguido, habita en una cueva del desierto y pensamos que asciende al cielo. Según los comentaristas, Taxo sería instituido sumo sacerdote en el cielo, según 10, 1; antes de morir, exhorta a sus hijos a seguir fieles a la Ley y aceptar el martirio siguiendo el tenor de 2 Mac 7, donde de modo similar hay una exhortatio ad martirium. En $1 \mathrm{Mac} 2,58$ presenta una relectura martirial que se hace de Elías durante este período: "por su celo de la Ley Elías fue arrebatado al cielo".

Las metáforas de la sangre derramada aparecen descritas en términos de una persecución religiosa en la que se asesina y se entierra a los héroes del pueblo en lugares desconocidos, así puede verse en pasajes de AscMoisés 6, 2: "un petulante rey sucederá a ellos, que no será del estirpe sacerdotal, un hombre malvado y cruel. Y él dominará sobre ellos como

36 G.E. Nickelsburg, Resurrection, Inmortality, and Eternal Life in Intertestamental Judaism and Early Christianity. Expanded Edition (Harvard University Press, New Haven, 2006) 62. 
ellos se merecen. Él matará a sus hombres de distinción y él enterrará sus cadáveres en lugares desconocidos, para que ninguno conozca dónde están sus cadáveres" y también en $6,8-7,10 ; 8,1-4$, se aprecia el motivo de la crucifixión, la tortura y renegar de su fe. En este último pasaje, se lee:

"y vendrá sobre ellos un segundo castigo y una cólera como no les había sucedido desde el comienzo del mundo hasta aquel momento, en el que suscitará contra ellos al rey de reyes de la tierra y soberano de gran poderío, que crucificará a quienes confiesen su circuncisión (qui confitentes cincumcisionem in cruce suspendit). $Y$ a quienes la nieguen torturará y entregará para que, aherrojados, sean conducidos a prisión. Y sus mujeres serán ofrecidas a los dioses de los gentiles, y sus hijos pequeños serán operados por puericultores para les rehagan el prepucio. Y otros entre ellos serán castigados con torturas, fuego y espada y serán forzados a llevar en público sus ídolos".

El relato de la Ascensión de Moisés presenta múltiples textos y detalles del tiempo final. El tema del asesinato en general o mediante crucifixión se repite en $6,3.8 ; 8,1 ; 9,6-7$. Las expresiones de tortura, purificación por tormentos, por medio de fuego y espada se repiten. Es notable la exhortatio ad martirium que realiza Taxo en 9, 6-7: "6 Muramos más bien que transgredir el mandato del Señor de señores, el Dios de nuestros padres. 7 pues así, nosotros debemos actuar y morir, nuestra sangre será vindicada ante Dios", que muestra un motivo que se volverá a repetir posteriormente según lo cual la muerte del mártir está en el contexto de la reivindicación de Dios.

\section{Resumen teológico}

En el relato de Ascensión de Moisés el motivo de la exaltación está referido al pueblo. La metáfora de la exaltación del pueblo está vinculada a la transformación en estrellas, como lo muestra AscMoisés 10, 9 “...y Dios te exaltará (Israel) y hará vivir en las estrellas del cielo”. También la ignorancia de la sepultura de Moisés como de los justos que siguen los mandatos de Dios es notable, pues refleja bien a las claras que la metáfora del arrebato está supuesta en el relato, según lo que ya hemos visto acerca de la equivalencia entre estar oculto y ser arrebatado; pero además la introducción de la terminología de la exaltación y la exhortatio ad martirium de 9, 6-7 expresan la actitud de desprecio ante la muerte y de desafío ante los enemigos tan característica de este género. También al igual que otros textos ya analizados, las metáforas están contrastadas 
con la metáfora de la muerte violenta de los justos o santos, sobre todo en $6,3.8 ; 8,1 ; 9,6-7$ en donde se puede apreciar que la metáfora de la exaltación es prometida a quienes son víctimas de crueles torturas y víctimas de asesinato.

\subsection{Testamento de los XII Patriarcas}

Ciertamente, en relación a esta 'revolutionary transformation' se constata que en la literatura posterior, se seguirá este mismo tenor. La riqueza es vista como señal de impiedad, no solo por enoquitas ${ }^{37}$ sino por los grupos que están detrás del Testamento XII Patriarcas y de Ecclo 13, 2-7.

La primera metáfora, en el Testamento de los XII Patriarcas, muestra en amplias partes la convicción de los sietes cielos $(3,1)$. En función de la prognosis que otorga la visión de los misterios celestes, el TestLeví 1, 6 relata la visión y arrebato de Leví a los cielos: "se abrieron los cielos y el ángel de Dios me dijo: Leví entra $(\epsilon i \sigma \in \lambda \theta \epsilon)$. Y entré ( $\epsilon i \sigma \eta \lambda \theta o \nu)$ en el primer cielo". En diversos momentos Leví es llevado: "entonces el án-

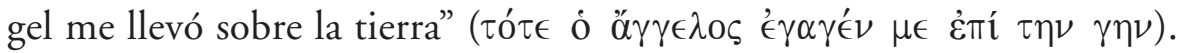
La evidente identificación entre abrir, ser llevado, entrar y ver muestra un imaginario en común en estos textos que está en función de una revelación entregada por Dios o el ángel al visionario; así como Enoch y Moisés, Leví es sujeto de revelaciones celestes lo cual legitima a este en cuanto sacerdote alternativo al sumo sacerdocio jerosolimitano, así como las aspiraciones ideológicas de su grupo.

En relación a la metáfora de la sangre martirial, se aprecia una continuidad con la tradición de las Parábolas de Enoch, ya que en algunos pasajes como TestJudá 25, 4, la negatividad de las promesas escatológicas se formulan en función de la mencionada inversión escatológica para aquellos que hayan muerto en tristeza, pobreza o necesidad por el Señor recibirán la promesa de la vida: "los que hayan muerto en la tristeza resucitarán en gozo, y los que hayan vivido en pobreza por el Señor se enriquecerán; los necesitados se hartarán; se fortalecerán los débiles y los muertos por el Señor se despertarán para la vida" (TestJudá 25, 4). Es notable esta secuencia pues refleja así como en las Parábolas de Enoch

37 Podemos apreciar esta opinión en 1En 94, 3 donde se dice 'Ay de vosotros los ricos porque habéis puesto vuestra confianza en la riqueza”; también en 1En 25, 4 dice "cuando Dios haya tomado venganza de todos y todo haya acabado para siempre, se dará este árbol a los justos y a los humildes". 
que "los muertos por el Señor" está en el contexto de una reivindicación escatológica del justo. Esto mismo lo encontramos reflejado en TestBenjamín 3, 6-8, que, además, como se puede apreciar, expresa el sentido expiatorio de su muerte "en ti se cumplirá la profecía del cielo que dice que el intachable será contaminado por hombres sin ley, y que él sin pecado morirá por hombres impios" 38 .

Pero además, la segunda metáfora, aparece en el Testamento XII Patriarcas que expresa que en los últimos tiempos, aumentará la violencia, la injusticia, los sacerdotes y jueces violan las leyes, etc. Con resignación el escriba señala que en los últimos días:

"Perseguiréis a los justos y odiaréis a los piadosos, abominando las palabras de quienes profieren verdad. Al hombre que renovará la Ley por la potencia del altísimo lo tacharéis de impostor y al final -tal como los pensasteis-, lo mataréis sin llegar a conocer su dignidad, permitiendo por vuestra maldad, que se derrame sangre inocente sobre vuestras cabezas" (ver Test Leví 17, 6-7; TestJudá 21, 7-9).

En este texto, justos y piadosos son perseguidos, al enviado por Dios lo acusarán de impostor, asesinando a este sin conocer su dignidad, derramando con esto sangre inocente.

\section{Resumen teológico}

En TestLeví se aprecia una clara identificación entre abrir, ser llevado, entrar y ver que muestra un imaginario común en estos textos que está en función de una revelación entregada por Dios o el ángel al visionario; así como Enoch y Moisés, Leví es sujeto de revelaciones celestes lo cual legitima a este en cuanto sacerdote alternativo al sumo sacerdocio jerosolimitano. Tanto el que asciende como el que ve abrirse los cielos contempla misterios que lo constituye en testigo (Jn 1, 18). Paradójicamente en estos textos como TestJudá 25, 4 y TestBenjamín 3, 6-8 se subraya el imaginario que la sangre martirial esta en función de la mencionada inversión escatológica para aquellos que hayan muerto en tristeza, pobreza o necesidad por el Señora: "los que hayan muerto en la tristeza resucitarán en gozo, y los que hayan vivido en pobreza por

38 También en la literatura rabínica (ver Sukkah 52b), a propósito del texto de Zac $12,12$. 
el Señor se enriquecerán; los necesitados se hartarán; se fortalecerán los débiles y los muertos por el Señor se despertarán para la vida".

Por consiguiente, recepción de una revelación y participación de los sufrimientos y martirio no parecen estar en un camino paralelo sino que son concomitantes con el tiempo final. En efecto, en estos textos el envío de Belial muestra la etapa final de la historia marcada por el incremento del mal en la creación. Este tiempo está marcado por la revelación de los misterios a los elegidos; el sentido de la historia, así como el predominio de la maldad aún sobre los que cumplen la voluntad de Yahvéh.

\section{Conclusiones}

Creemos haber mostrado en nuestro estudio que estas dos metáforas pertenecen a un mismo imaginario y que ambas metáforas tienen su particular enraizamiento histórico, político-cultural y pertenecen al imaginario del martirio. La experiencia de la muerte violenta sufrida por grupos judíos durante el periodo que se abre con el dominio griego, se enmarca dentro de una interpretación político-escatológica de la historia que postula el triunfo de la justicia. En este contexto, el martirio en cuanto experiencia histórica se constituye en lugar teológico que integra múltiples imágenes y metáforas que postulan el triunfo de la justicia en la historia, como p.e.: "brillar como estrellas", ser "transformados como ángeles", "ser entronizados" o "resucitar". Si atendemos a la influencia que este imaginario judío tuvo en la redacción de la fórmulas pascuales cristianas tendremos que caer en la cuenta que estas nacen de manera simultánea y no por separado como acostumbra a postular la exégesis europea del siglo pasado. No obstante que dejamos abierta la respuesta. Hay que decir lo siguiente. Si estas dos metáforas son parte integral de un imaginario que dio sentido a la entrega en el sufrimiento, tortura e incluso muerte humillante de diversos individuos o grupos judíos, parece extraño, hasta rebuscado, argumentar que el sentido de la muerte de Jesús de Nazaret haya que buscarlo en un interpretación post-pascual y en suelo helenista (Mc 10, 45; 14,24; 1 Cor 15, 3) como lo postula la exegesis habitualmente.

Los textos apocalípticos analizados, presentan un imaginario que desarrolla metafóricamente, una ideología de la estratificación del cosmos, que sostiene que el pobre es el justo que sufre en un mundo empecatado e injusto. Hemos señalado que las metáforas del arrebato y del derrama- 
miento de la sangre inocente son una contra-ideología, en función de una prognosis del martirio. Por lo tanto estas metáforas apuntan a una superación positiva del sinsentido de la muerte del justo. En ese sentido, dichas metáforas son un dispositivo-esperanza de un imaginario que intenta superar una interpretación legalista de la religión o de la persecución secular que proclama el triunfo de la injusticia y la muerte violenta. Los relatos no apuntan meramente a una cuestión de la vida más allá de la muerte, en términos metafísicos, sino que su núcleo radica en la proclamación del triunfo de la justicia divina y en la transformación de las víctimas políticas en actores escatológicos de la justicia divina. En el caso de Jubileos, el papel del enviado o testigo está en función de entregar su vida en medio de su pueblo. Como hemos visto, la metáfora de la sangre derramada recurre al paradigma de Abel, según el cual, son las víctimas históricas quienes juzgarán al mundo en el eschaton. En los textos de las 1Enoch, Parábolas de Enoch, Epístola de Enoch, Daniel, Ascensión de Moisés así como en el Test XII Patriarcas aparece como núcleo de este imaginario, una valoración positiva de la pobreza así como del padecer o morir por Dios; esta paradoja responden a una inversión escatológica propia del pensamiento apocalíptico que fecundó la convicción de las víctimas en su lucha por la justicia y en donde se fraguó tanto el anuncio de la inminencia del juicio como la convicción en la exaltación del Justo. Por tanto no es casualidad que en los diversos textos analizados, p.e., en Dn 7, 11-12; AscMoisés 10, 9, se postula que la promesa de la resurrección tanto al pueblo, a los 'santos', como al Justo en su condición de testigos o para aquellos que han luchado por la justicia en este mundo.

Tomando en consideración nuestro punto de partida acerca de un regreso a la apocalíptica en la teología latinoamericana se impone una conclusión desde los textos bíblicos. Es en la lucha por la justicia en donde la teología encuentra el centro de su fe en la resurrección y, por consiguiente, será en el encuentro con los mártires y justos del continente donde encontrará hoy el mensaje de la resurrección. El análisis anterior nos lleva a afirmar que la verificación de la fe en una vida trascendente se evalúa en la lucha por la justicia de Dios en la historia. Por tanto, es la propia convicción escatológica la que impulsa al creyente al plano político, esto explica, algo obvio sin duda, que las formulaciones de la victoria de la justicia, tal como las encontramos en el NT, entendida como resucitar, exaltación o convertirse en ángeles fueron experimentadas y proclamadas no por los verdugos sino por las víctimas. 
Resumen: El artículo expone antecedentes del imaginario del martirio en la apocalíptica judía, la cual se puede constatar a través del estudio de dos metáforas: la del arrebato al cielo y la sangre derramada de los justos. La apocalíptica en cuanto pensamiento estético, desarrolla dicha metafórica en grupos marginales judíos quienes al regreso del destierro comienzan a elaborar un proyecto histórico fundado en una metafórica de la entrega de la vida por el pueblo o por Dios, con su posterior exaltación a los cielos. Este imaginario se caracteriza fundamentalmente como una interpretación político-escatológica de la muerte causa de la justicia de Dios, que muestra una nueva racionalidad de dar la vida por la justicia divina.

Palabras clave: Estética, martirio, justicia, arrebato, negatividad, escatología.

Abstract: The Article exposes the imaginary antecedents of martyrdom in Jewish apocalyptic, which can be seen through the Study of two Metaphors: the Rapture to Heaven and the Blood of the Righteous. The apocalyptic as aesthetic thought, develops such metaphorica in marginal groups Jews who returned from exile to begin to develop a historical project based on a metaphorical delivery of life by the people or by God, with his subsequent exaltation to Heaven. This imagery is mainly characterized as a political-eschatological interpretation of Death because of the Justice of God, which shows a new rationality of giving life by divine justice.

Keywords: Aesthetic, martyrdom, justice, rapture, negativity, eschatology. 
